\title{
Inhibition Performance of Eugenol and Linalool on Aluminium Corrosion: A Comparative Study
}

\author{
Jasna Halambek ${ }^{1, *}$, Antonela Ninčević Grassino ${ }^{2}$ and Ines Cindrićl \\ ${ }^{1}$ Karlovac University of Applied Sciences, Department of Food Technology, Trg J.J. Strossmayera 9, \\ 47000 Karlovac, Croatia \\ ${ }^{2}$ Faculty of Food Technology and Biotechnology, Department of Chemistry and Biochemistry, \\ Pierottieva 6, 10000 Zagreb, Croatia \\ *E-mail: jasna.halambek@vuka.hr
}

doi: $10.20964 / 2020.01 .71$

Received: 25 September 2019 / Accepted: 7 November 2019 / Published: 30 November 2019

\begin{abstract}
It is well known that corrosion inhibition performance of organic compounds in acidic media depend on their concentration and molecular structures. Therefore, the comparative study of inhibition efficiency of eugenol as aromatic and linalool as linear molecules on aluminium corrosion in $0.5 \mathrm{M} \mathrm{HCl}$ solution was performed. The study was done by weight loss, potentiodynamic polarization and EIS methods, while surface morphology of aluminium was examined by SEM method. All used methods confirmed inhibition efficiency of both investigated compounds on aluminium corrosion in acidic medium. From the obtained potentiodynamic polarization curves is evident that presence of eugenol and linalool in acid media cause a prominent decrease in current densities, and shift of the $E_{\text {corr values to more cathodic }}$ direction in comparison with $0.5 \mathrm{M} \mathrm{HCl}$ without inhibitors. EIS method confirmed that the maximum inhibition was achieved with addition of $0.012 \mathrm{~mol} \mathrm{~L}^{-1}$ eugenol $(92.4 \%)$ and $0.035 \mathrm{~mol} \mathrm{~L}^{-1}$ linalool $(85.1 \%)$ in $\mathrm{HCl}$ solution. Thus, these concentrations can be assumed as optimum for corrosion inhibition of aluminium. SEM results are in accordance with the results obtained by weight loss and electrochemical measurements, confirming the existence of protective inhibitor film on the Al surface.
\end{abstract}

Keywords: aluminium, corrosion, eugenol, inhibition, linalool.

\section{FULL TEXT}

(C) 2020 The Authors. Published by ESG (www.electrochemsci.org). This article is an open access article distributed under the terms and conditions of the Creative Commons Attribution license (http://creativecommons.org/licenses/by/4.0/). 